\title{
Effect in self-care behavior and difficulties in coping with diabetes during the COVID-19 pandemic
}

\section{Efecto en el comportamiento de autocuidado y dificultades para hacer frente a la diabetes durante la pandemia de COVID-19}

\author{
Rubén Silva-Tinoco ${ }^{1 *}$, Arnulfo GonzÁlez-Cantí2 2,3 , Viridiana De la Torre-Saldaña ${ }^{1}$, \\ Eileen GuZmán-Olvera ${ }^{1}$, Teresa Cuatecontzi-Xochitiotzi ${ }^{1}$, Lilia Castillo-Martínez ${ }^{4}$, \\ Ma. Elena Romero-Ibarguengoitia ${ }^{2,3}$, Areli Nahuacatl-LóPeZ ${ }^{1}$, CARMen Castillo-Galindo ${ }^{1}$, \\ Arturo Orea-Tejeda ${ }^{5}$, Javier Serna-Alvarado ${ }^{6}$, Enrique León-García ${ }^{6}$ and Jorge Ochoa-Moreno ${ }^{6}$
}

\begin{abstract}
${ }^{1}$ Clinic Specialized in the Diabetes Management of the Mexico City Government, Servicios de Salud Pública del Gobierno de la Ciudad de México, Mexico City; ${ }^{2}$ Department of Research and Teaching, Hospital Clínica Nova, San Nicolás de los Garza, Nuevo León; ${ }^{3}$ School of Medicine, Universidad de Monterrey, San Pedro Garza García, Nuevo León; ${ }^{4}$ Department of Clinical Nutrition, Instituto Nacional de Ciencias Médicas y Nutrición Salvador Zubirán, Mexico City; ${ }^{5}$ Department of Cardiology, Instituto Nacional de Enfermedades Respiratorias Ismael Cosío Villegas, Mexico City; ${ }^{6}$ Public Health Services, Mexico City Government, Mexico City. Mexico
\end{abstract}

\section{ABSTRACT}

In this study, difficulties in coping with diabetes were evaluated during the coronavirus disease 2019 (COVID-19) lockdown. Similarly, the change in diabetes self-care activities was evaluated in patients with a recent assessment before COVID-19 lockdown in Mexico City. In 212 patients with type 2 diabetes (T2D) and regular primary care, a designed questionnaire was used to evaluate the presence/absence of difficulties in self-care related to diet, physical activity/exercise, glucose monitoring, treatment adherence, getting pharmacological treatment, and confinement adherence. The Summary of Diabetes Self-Care Activities tool was used to compare the frequency of self-care behaviors in the past 7 days. Self-reported difficulties in coping with T2D were documented and included difficulties in self-care behaviors related to diet (41.6\%), physical activity/exercise $(40.5 \%)$, glucose monitoring $(23.7 \%)$, getting pharmacological treatment (22.9\%),
RESUMEN

En el presente estudio se evaluaron las dificultades para hacer frente a la diabetes por los pacientes durante el confinamiento por COVID-19. Así mismo, se evaluó el cambio en las actividades de autocuidado de diabetes en pacientes con evaluación reciente antes del confinamiento por COVID-19 en la Ciudad de México. En 212 pacientes con diabetes tipo 2 (DT2), se utilizó un cuestionario diseñado para evaluar la presencia/ausencia de dificultades para el autocuidado. La herramienta Summary of Diabetes Self-Care Activities (SDCA) se utilizó para comparar las actividades de autocuidado, reportado en días a la semana. Las dificultades reportadas por los pacientes incluyeron las relacionadas con: alimentación (41.6\%), actividad física/ejercicio (40.5\%), monitoreo de glucosa $(23.7 \%)$, acceso al tratamiento farmacológico (22.9\%), adherencia al tratamiento farmacológico (19\%) y adherencia al confinamiento (11.7\%). En el grupo de pacientes con una
Correspondencia:

*Rubén Silva-Tinoco

E-mail: rosilva@sersalud.df.gob.mx
Fecha de recepción: 08-06-2020

Fecha de aceptación: 17-06-2020

DOI: 10.24875/RME.20000063
Disponible en internet: 15-07-2020

Rev Mex Endocrinol Metab Nutr. 2021;8:13-9

2462-4144 / ( 2020 Sociedad Mexicana de Nutricion y Endocrinologia, AC. Publicado por Permanyer. Éste es un artículo open access bajo la licencia CC BY-NC-ND (http://creativecommons.org/licenses/by-nc-nd/4.0/). 
pharmacological treatment adherence (19\%), and home-confinement adherence $(11.7 \%)$. In the group of patients with a recent previous-lockdown evaluation, global self-care behavior decreased from $5.15 \pm 0.9$ to $4.49 \pm 1.02$ days/week, $p<0.001$. Diabetes self-care was a predictor for the presence of difficulties in coping with diabetes. Patients with T2D reported difficulties in coping with T2D and decreased diabetes self-care activities during the COVID-19 lockdown in Mexico City. Health-care policies must be designed and implemented to attenuate diabetes disease burden caused by this ongoing and future health-contingencies.

Key words: Diabetes self-care. Self-care behavior. Coronavirus disease 2019. Lockdown.

\section{INTRODUCTION}

The coronavirus disease 2019 (COVID-19) outbreak caused by severe acute respiratory syndrome coronavirus 2 was first reported in Wuhan, China, and now has evolved into a global pandemic ${ }^{1}$. Patients with pre-existing conditions such as type 2 diabetes (T2D) mellitus, obesity, and cardiovascular disease, among others, have a higher risk of developing more severe disease ${ }^{2}$. According to the Centers for Disease Control and Prevention, patients with T2D and metabolic syndrome might have up to 10-times greater risk of death when they contract COVID-193. Hyperglycemia leads to a suppressed immune state and predisposes patients to infections, making glycemic control an important variable to reduce the risk and severity of COVID-194.

In Mexico, the Federal Government suggested quarantine to people susceptible for severe COVID-19, including older than 60 years and patients with T2D, among others. Globally, strategies established to reduce the virus spread include physical distancing and lockdown, which can be an additional burden for the patients, since they produce a notable emotional impact with symptoms of anxiety, stress, and depression ${ }^{5}$.

Social restrictions and emotional distress may have a negative impact on the comprehensive management of T2D, including metabolic control, self-care behaviors, and self-care management ${ }^{6}$. Diabetes self-care activities are behaviors undertaken by T2D patients and contribute to successful self-management ${ }^{7,8}$. evaluación reciente previa al confinamiento, la actividad global de autocuidado disminuyó de $5.15 \pm 0.9$ a $4.49 \pm 1.02$ días/semana, valor $p<0.001$. El autocuidado en diabetes fue predictor de la presencia de dificultades para hacer frente a la diabetes. Los pacientes informaron dificultades para afrontar la diabetes y disminuyeron las actividades de autocuidado durante el confinamiento por COVID-19. Políticas de atención médica deben diseñarse e implementarse para atenuar la carga de la enfermedad causado por esta y futuras contingencias en salud.

Palabras clave: Autocuidado diabetes. Autocuidado salud. COVID-19. Confinamiento.

These self-care behaviors positively correlate with good glycemic control, reduction of complications, and improvement in the quality of life ${ }^{7,9}$.

Lockdown may impose difficulties for executing self-care activities since some of them are dependent on leaving home to be able to execute them. Moreover, information is lacking regarding the impact and health needs among patients living with T2D during and after the COVID-19 outbreak, but also about consequences related to the lockdown and social distancing on diabetes care goals, including diabetes self-care. Therefore, the aim of this study was to evaluate the effect of the COVID-19 pandemic on diabetes self-care behavior and to know the difficulties in coping with diabetes during the lockdown in persons living with T2D.

\section{MATERIALS AND METHODS}

\section{Subjects}

An observational cross-sectional survey was conducted among 212 patients with T2D who registered a visit for dispensing medications in the pharmacy of Clínica Especializada en el Manejo de la Diabetes from the Mexico City government during the COVID-19 health contingency between April 20, 2020, and May 29, 2020. Patients were participants of the Diabetes EMPowerment and Improvement of Care (DIABEMPIC) program, whether they had finished the program recently (previous 2 months) or 
were ongoing. The DIABEMPIC program is a quality improvement-of-care initiative in the public primary health-care system, designed to improve clinical outcomes for patients with T2D through multicomponent intervention, including interdisciplinary care and self-management education scheme ${ }^{7,10-12}$. These patients were referred from primary outpatient centers located in urban areas of Mexico City, they were beneficiaries of the INSABI (public health insurance), and some of them continue to receive medication at the Clinic when they finished the program. The study protocol was approved by the ethics and investigation in humans' committee Institutional Review Board (101-010-019-20). The DIABEMPIC study was registered in ClinicalTrials.gov (Identifier: NCT04245267). The participation criteria were as follows: (a) T2D patients older than 18 years and (b) acceptance to participate after explaining the survey and the questionnaire. The data related to demographic characteristics, time since diagnosis, and comorbidities were collected from medical records and confirmed during the interviews.

\section{Self-reported difficulties and self-care assessment}

A questionnaire was used to identify the presence/ absence of difficulties for coping with T2D during the COVID-19 lockdown. The questionnaire included components related to difficulties for self-care related to diet, physical activity/exercise, glucose monitoring, treatment adherence, getting pharmacological treatment, and difficulties for confinement adherence for working purposes. For example, for self-care difficulty related to diet, the question was as follows: During this COVID-19 lockdown, do you have difficulties related to the lockdown in following recommendations for diet self-care? The 11-item version of the Summary of Diabetes Self-Care Activities ${ }^{13}$ was used to measure the frequency of selfcare behavior in the past 7 days. In this study, we report a global self-care behavior score (average of diet, physical activity/exercise, glucose monitoring, and foot-care behaviors) reported in days a week patient executes self-care activities. Global self-care score was also previously measured in patients who completed the DIABEMPIC program between
February 2020 and March 2020, so a comparative analysis with this group of patients was possible. After getting their reply, an appointment for telephone consulting was scheduled for advice about any inquiries related to their T2D management.

\section{Statistical analysis}

The normality of the variables was explored through the Shapiro-Wilk test. Categorical variables were presented as frequency and percentage, and continuous variables as mean and standard deviation (SD). To compare global self-care activities, previous-lockdown global self-care score versus during-lockdown global self-care score, a paired-sample t-test was performed. To predict the presence of self-reported difficulties, a generalized linear model with a quasibinomial link function was used. This link function addresses the over-dispersion of the data, making stricter the omnibus test. Multiple correspondence analyses were used to generate a map to show the spatial relationship between questionnaire variables. It was considered a two-tail study and a $p<0.05$ was considered statistically significant. Missing values were managed by complete case analysis. The sample size was computed by convenience since it included all subjects that completed the DIABEMPIC program that accepted to participate answering the questionnaire. The statistical programs used as SPSS version 21 (IBM, Armonk, NY, USA).

\section{RESULTS}

A total of 212 patients with T2D were included in the study. Most patients were female (61.3\%), 50.4\% had hypertension, and according to the body mass index criteria, $41.9 \%$ had obesity. The mean age was $54.3 \pm 10.9$ years, and mean disease duration was $11.4 \pm 7.7$ years.

In table 1, the clinical characteristics of the study population and self-reported difficulties for self-care performance are presented. The variables with higher self-reported difficulties were diet (41.6\%), physical activity/exercise (40.5\%), and glucose monitoring 
Table 1. Clinical characteristics of the study population $(n=212)$

\begin{tabular}{lc}
\hline Characteristics & $\mathrm{n}=212$ \\
\hline Female, \% & $130(61.3)$ \\
\hline Age, years & $54.3 \pm 10.9$ \\
\hline Primary school or less education & $89(41.9)$ \\
\hline Diabetes duration, years & $11.4 \pm 7.7$ \\
\hline Age at diagnosis, years & $43,5 \pm 10.3$ \\
\hline Hypertension, \% & $107(50.4)$ \\
\hline Obesity (body mass index), \% & $89(41.9)$ \\
\hline Self-reported difficulties for self-care performance & $88(41.5)$ \\
- Diet & $85(40)$ \\
- Physical activity/exercise & $50(23.5)$ \\
- Monitoring glucose & $40(18.8)$ \\
- Treatment adherence previous weeks & $48(22.6)$ \\
- Confinement adherence & $25(11.7)$
\end{tabular}

Data are presented as number (percentage) or mean \pm standard deviation as indicated.

Table 2. Quasibinomial regression models for pre-pandemic and pandemic global self-care behavior scores and the presence of difficulties

\begin{tabular}{lllll}
\hline Variable & Estimate & $\exp (\beta)$ & $95 \%$ CI & $\mathrm{p}$ - value \\
\hline Diet model & & & & \\
\hline Pre-pandemic global self-care & -0.53 & 0.58 & $0.37-0.9$ & 0.015 \\
\hline During pandemic global self-care & -0.84 & 0.42 & $0.26-0.69$ & $<0.001$ \\
\hline Exercise model & & & & \\
\hline Pre-pandemic global self-care & -0.47 & 0.62 & $0.4-0.95$ & 0.031 \\
\hline During pandemic global self-care & -0.67 & 0.51 & $0.32-0.79$ & 0.003 \\
\hline Medication model & & & & \\
\hline During pandemic global self-care & -0.5779 & 0.56 & $0.32-0.97$ & 0.038 \\
\hline
\end{tabular}

$\operatorname{Exp}(\beta)$ refers to odds ratio.

(23.7\%). In the group of patients with a recent previous-lockdown evaluation $(n=106)$, the global selfcare activities score decreased from $5.15 \pm 0.9$ to $4.49 \pm 1.02$ days/week, $\mathrm{p}<0.001$ (Fig. 1).

Pre-pandemic and pandemic global self-care behavior scores were significant predictors in the quasibinomial regression models (Table 2). A pre-pandemic high score in the self-care behavior scale was related to fewer difficulties in diet and exercise $(p<0.05)$. A high global self-care behavior score during pandemic had also an inverse relation with difficulties in diet, exercise, and medication $(p<0.05)$.
Multiple correspondence analyses reduced the questionnaire in two dimensions, and it explained $62.8 \%$ of the variance. Figure 2 shows the spatial relationship between variables; variables answered as "no difficulties" were colored black and "with difficulties" were colored gray. Dimension one did not split the variables, but dimension two splitted the data in two groups: one by no difficulties in the medication attachment and other with the rest of the answers. This clustering expressed the inverse relationship between no difficulties in medication attachment and the rest of difficulties explored by the questionnaire. 


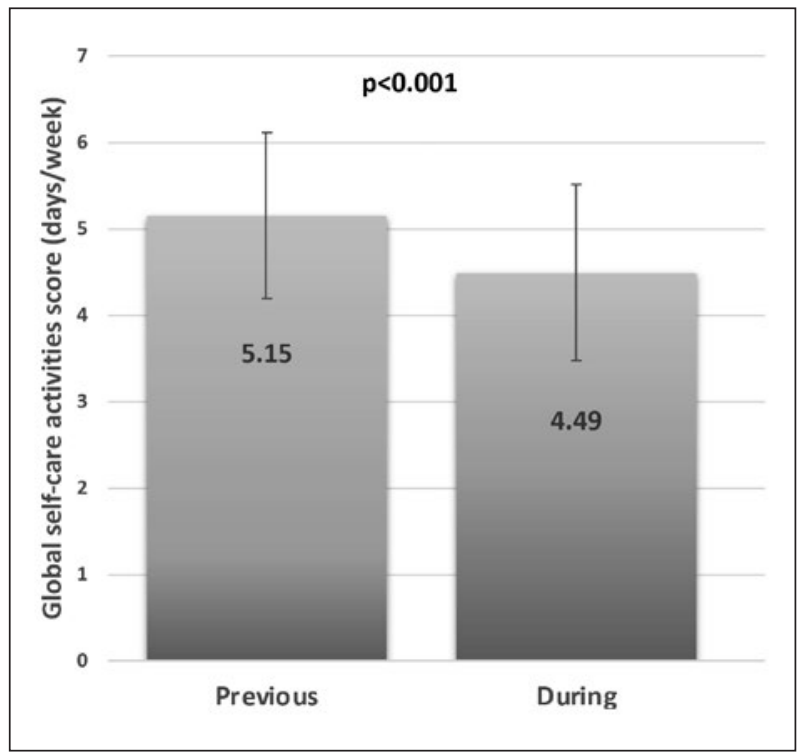

Figure 1. Previous and during coronavirus disease 2019 lockdown global self-care activities score (days a week) in Mexico City $(n=106)$. Data are expressed as mean of global self-care score (diet, physical activity/exercise, glucose monitoring, and foot care) in days a week.

\section{DISCUSSION}

This study aimed to analyze the effect in self-care behavior and the presence of difficulties in coping with diabetes treatment during the COVID-19 lockdown in patients with regular primary care in Mexico City. Remarkably, patients with T2D reported a high frequency of difficulties for self-care behavior performance, particularly for coping with a diet plan and exercise recommendations. In addition, patients decreased global self-care behavior during the COVID-19 outbreak, but patients with better self-care behavior performance reported less difficulty in coping with diabetes. To the best of our knowledge, this is one of the first studies demonstrating the effect of the COVID-19 lockdown in diabetes self-care behavior and the presence of difficulties in coping with diabetes in patients living with T2D.

The evidence about the barriers and difficulties for the management of disease in patients with T2D imposed by COVID-19 is scant. Nachimuthu S. reported regular adherence to exercise and diet in India, but only $28 \%$ of patients surveyed were

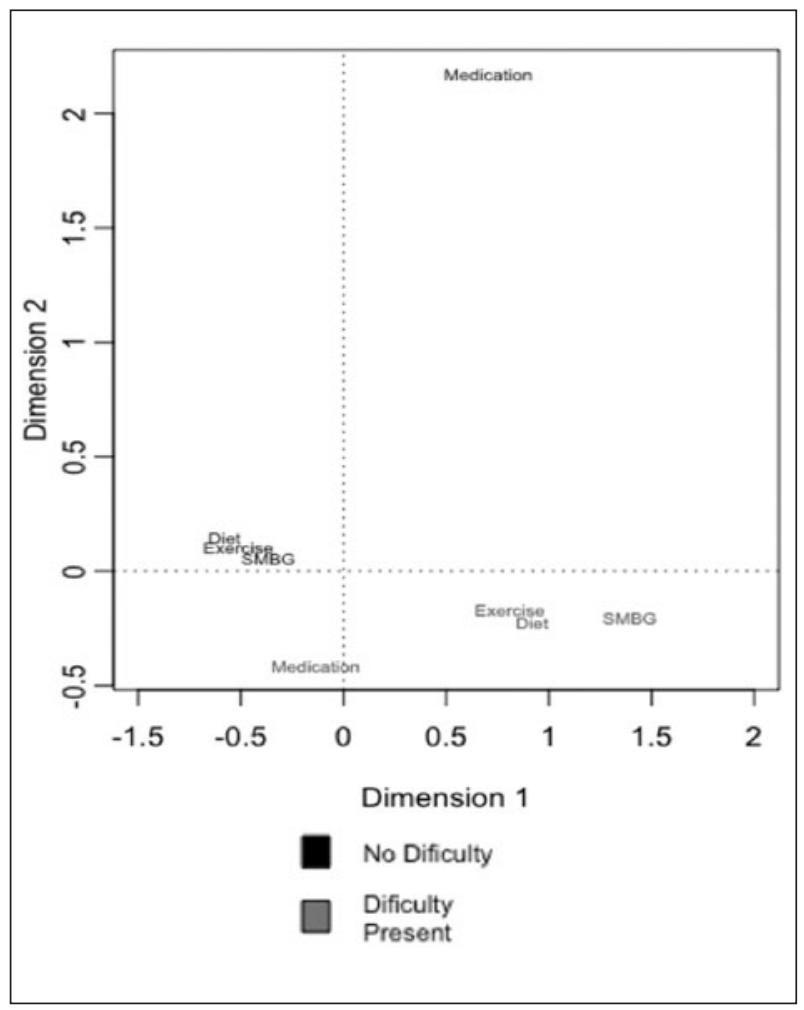

Figure 2. Spatial relationship between variables of the difficulties related to self-care questionnaire. SMBG: self-monitoring blood glucose. This map is constructed with the first two dimensions acquired by multiple correspondence analysis. The variances represented by the first two dimensions were $38.7 \%$ and $24.1 \%$, respectively.

checking their blood glucose levels during COVID-19 lockdown ${ }^{14}$. In this work, we report not only the presence of difficulties in coping with diabetes but also a comparison between the current-lockdown diabetes self-care with that before the lockdown.

Diabetes requires lifelong behavioral modifications for effective treatment, such as regular exercise, dietary changes, frequent blood glucose testing, and medication adherence ${ }^{15}$. Previously, we reported worst outcomes related to deficits in self-care and disease knowledge in patients with T2D in the primary care setting, which improved with a multicomponent intervention focused on diabetes therapeutic education and self-care behaviors changes ${ }^{7,11,12}$.

The COVID-19 lockdown imposed different barriers to continue with disease self-care by patients with T2D. The restriction to stay at home difficult to make decisions about the food consumed, to exercise at 
open spaces or sports centers, and to obtain medications ${ }^{14}$. In this study, a significant proportion of patients reported that these confinement-induced difficulties to continue their care related to diet, physical activity and exercise, and glucose monitoring. Similarly, patients had difficulties in accessing their pharmacological treatment and attending the recommendation of confinement due to the need to continue working.

Furthermore, many patients stopped attending their routine medical appointments in health centers during this lockdown, because of either the risk of contagion or the lack of capacity of the overwhelmed health-care system by COVID-19 patients. Multiple actions can be implemented to handle these problems, such as telemedical care, improvements in the dispensing of medications, psychological support, and counseling to continue their diabetes self-care ${ }^{6,16,17}$.

In our study, better pre-pandemic self-care behavior was related to less difficulty in diet and exercise. A high self-care behavior score reported during pandemic had also an inverse relation with difficulties in diet, exercise, and medication. This could reflect that when a patient has better self-care activities performance, it is more likely to have better diabetes management in health contingencies scenarios, and patients are less dependent on the health-care system to continue managing their disease. Therefore, effective strategies focused on improving selfcare and provide self-efficacy in regular care should be considered to decrease diabetes disease burden in these scenarios ${ }^{7,18,19}$.

Although these results are novel and potentially useful in COVID-19 lockdown in patients with T2D and regular primary care, our study has several limitations. First, this is a cross-sectional exploratory study, so we are not able to conclude causality; even though a longitudinal analysis of self-care was done, it is not possible to conclude that the decrease in self-care was not influenced for other variables that were not included in this study. However, as any other epidemiological study, it is a hypothesis generator, and it examines the impact of the COVID19 lockdown in an important determinant of health in diabetes, just like self-care and medication adherence. Second, the studied population belongs to a group of patients with a recent finished diabetes multicomponent intervention, so this decrease in self-care was observed in patients with a previous high self-care performance. Nevertheless, people with the absence of this kind of quality of care interventions may have lower skills in coping with diabetes, then the negative impact of COVID-19 lockdown could be even greater in these populations. Third, we report only the presence of difficulties for diabetes self-care, but the causes that explain each difficulty is not evaluated, so a wider causal research study are recommended. In this work, the presence of difficulties related to self-care habits such as glucose monitoring, physical activity/ exercise, and diet were clustered with each other, but not with medication adherence (Fig. 2), suggesting associations between barrier mechanisms. The effect of the economic impact caused by this quarantine, which conditioned the loss of economic incomes in many households, is an aspect that must be investigated as a barrier to carrying out self-care and adherence actions, particularly in populations with social backwardness. Finally, this study was performed in a single center; thus, a center-specific bias cannot be excluded from the study. However, it is a reference center for other health-care units within the first level of care in the public health system, so it may be a representative sample of patients with diabetes in Mexico City. Moreover, the study highlights the need to consider difficulties in coping with diabetes across populations that surely share similarities with our sample.

\section{CONCLUSIONS}

The COVID-19 lockdown affects diabetes self-care performance and imposes difficulties in coping with diabetes in patients with T2D. Diabetes self-care was a predictor for the presence of difficulties in coping with diabetes. Futures studies about the impact on diabetes care goals are guaranteed. Health-care policies must be designed and implemented to attenuate diabetes disease burden caused by this ongoing and future health-contingencies. 
Approval was obtained by the institutional Bioethics and Research Health Ministry Board (101-010-019-20).

\section{CONFLICTS OF INTEREST}

The authors declare that they have no conflicts of interest.

\section{FUNDING}

No public or private funding was available for this research.

\section{ETHICAL DISCLOSURES}

Protection of human and animal subjects. The authors declare that no experiments were performed on humans or animals for this study.

Confidentiality of data. The authors declare that they have followed the protocols of their work center on the publication of patient data.

Right to privacy and informed consent. The authors declare that no patient data appear in this article.

\section{REFERENCES}

1. COVID-19: cronología de la Actuación de la OMS. Available from: https:// www.who.int/es/news-room/detail/27-04-2020-who-timeline--covid-19.

2. Wu Z, McGoogan JM. Characteristics of and important lessons from the coronavirus disease 2019 (COVID-19) outbreak in china: summary of a report of 72314 cases from the Chinese center for disease control and prevention. JAMA. 2020;323:1239-42.

3. Bornstein SR, Dalan R, Hopkins D, Mingrone G, Boehm BO. Endocrine and metabolic link to coronavirus infection. Nat Rev Endocrinol. 2020;16:297-8

4. Singh AK, Gupta R, Ghosh A, Misra A. Diabetes in COVID-19: prevalence, pathophysiology, prognosis and practical considerations. Diabetes Metab Syndr Clin Res Rev. 2020;14:303-10.

5. Wang C, Pan R, Wan X, Tan Y, Xu L, Ho CS, et al. Immediate psychological responses and associated factors during the initial stage of the 2019 coronavirus disease (COVID-19) epidemic among the general population in China. Int J Environ Res Public Health. 2020;17:1729.

6. Banerjee M, Chakraborty S, Pal R. Diabetes self-management amid COVID-19 pandemic. Diabetes Metab Syndr Clin Res Rev. 2020;14:351-4.

7. Silva-Tinoco $R$, Cuatecontzi-Xochitiotzi $T$, De la Torre-Saldaña $V$, LeónGarcía E, Serna-Alvarado J, Guzmán-Olvera E, et al. Role of social and other determinants of health in the effect of a multicomponent integrated care strategy on Type 2 diabetes mellitus. Int J Equity Health. 2020;19:75.

8. Shrivastava SR, Shrivastava PS, Ramasamy J. Role of self-care in management of diabetes mellitus. J Diabetes Metab Disord. 2013;12:14.

9. Ausili D, Bulgheroni M, Ballatore P, Specchia C, Ajdini A, Bezze S, et al Self-care, quality of life and clinical outcomes of Type 2 diabetes patients: an observational cross-sectional study. Acta Diabetol. 2017; $54: 1001-8$

10. Silva-Tinoco R, Meza DG, Martinez DG, Orozco J, Romero-lbarguengoitia $M E$, Torre-Saldañ V, et al. Diabetes self-management education program effect on glycemic control and insulin dosing in poor diabetes literacy patients from urban areas in Mexico city therapeutic education underuse and insulin overuse. Diabetes. 2018;67 Suppl 1:658.

11. Silva-Tinoco $R$, Cuatecontzi ET, Alonso AG, Romero-Ibarguengoitia ME, Torre-Saldañ V, Cabrera-Gerardo MD, et al. interdisciplinary educative structured diabetes program effect on health-related quality of life and anxiety/depression perception in patients attending a primary care diabetes clinic in Mexico city. Diabetes. 2018;67 Suppl 1:687.

12. Delatorre-Saldaña VA, Silva-Tinoco R, Hernández J, Guzman EB, Castillo-Martínez L, Orea-Tejeda A, et al. 655-P: effect of an interdisciplinary care and diabetes self-management education program on weigh among persons with social and clinical complex profile. Diabetes. 2019;68 Suppl 1:655.

13. Toobert DJ, Hampson SE, Glasgow RE. The summary of diabetes self-care activities measure: results from 7 studies and a revised scale. Diabetes Care. 20001;23:943-50

14. Nachimuthu S, Vijayalakshmi R, Sudha M, Viswanathan V. Coping with diabetes during the COVID 19 lockdown in India: results of an online pilot survey. Diabetes Metab Syndr Clin Res Rev. 2020;14:579-82.

15. American Association of Diabetes Educators. An effective model of diabetes care and education: revising the AADE7 self-care behaviors ${ }^{\circledR}$. Diabetes Educ. 2020:46:139-60.

16. World Health Organization. Mental Health and Psychosocial Considerations during the COVID-19 Outbreak, 18 March 2020. Geneva: World Health Organization; 2020. Available from: https://www.who.int/docs/ default-source/coronaviruse/mental-health-considerations.pdf.

17. Hu Y, Wen X, Wang F, Yang D, Liu S, Li P, et al. Effect of telemedicine intervention on hypoglycaemia in diabetes patients: a systematic review and meta-analysis of randomised controlled trials. J Telemed Telecare. 2019;25:402-13.

18. Hernández-Jiménez S, García-Ulloa AC, Bello-Chavolla OY, Aguilar-Salinas CA, Kershenobich-Stalnikowitz D. Long-term effectiveness of a Type 2 diabetes comprehensive care program. The CAIPaDi model. Diabetes Res Clin Pract. 2019;151:128-37.

19. Whittemore R, Vilar-Compte $M$, De La Cerda S, Delvy R, Jeon S, Burrola-Méndez $S$, et al. ¡Sí, yo puedo vivir sano con diabetes! A self-management randomized controlled pilot trial for low-income adults with Type 2 diabetes in Mexico city. Curr Dev Nutr. 2020;4:nzaa074. 